\title{
Liquidity Provision and Banking Crises with Heterogeneous Agents
}

\author{
Matias Fontenla* \\ University of New Mexico
}

February 15, 2007

\begin{abstract}
The banking literature following the original Diamond and Dybvig (1983) model has assumed that all depositors are ex ante identical. This paper relaxes this assumption by introducing two types of agents. While some agents are uncertain about their liquidity needs at the time they deposit in banks, other agents know exactly at what time they will want to withdraw their funds. Agents who know ex ante that they will want to withdraw in the short term will tend to disrupt the ability of a bank to serve customers who are uncertain about their timing of withdrawal. An adverse selection problem arises, where short-term deposits, which in our model turn out to be detrimental, have the incentive to join the financial system and limit, or completely do away with, bank's liquidity provision service. On the other hand, potentially beneficial long-term funds will not be deposited in banks. Further, when unpredicted short term withdrawal needs are sufficiently high, bank reserves are exhausted, and long-term investments need to be disrupted, causing a banking crisis.
\end{abstract}

\section{Introduction}

Following the models of Bryant (1980) and Diamond and Dybvig (1983), the banking literature has assumed that all agents who would potentially deposit in a bank are ex ante identical. In particular, all agents are equally attractive to a bank as potential customers. This paper examines a simple deviation from this assumption. While some agents are uncertain about their liquidity needs at the time they deposit in banks, other agents know exactly at what time they will want to withdraw their funds. Based on the previous literature, one might conjecture that the two types would endogenously segregate into separate banks, or banking contracts, that are designed to meet their unique needs. This

${ }^{*}$ I would like to thank Todd Keister, Neil Wallace, Dean Corbae and Russell Cooper for their comments, and Bruce Smith and Scott Freeman for inspiring me to work on this line of research. Part of this work was completed at the Universidad de Guanajuato and CIDE. All errors and omissions are mine alone. contact: fontenla@unm.edu. 
paper shows this is not the case. Instead, agents who are "less attractive" as depositors, because they are more likely to need to withdraw their funds at an earlier time, will tend to disrupt the ability of a bank to serve more attractive customers.

When depositors face ex ante uncertainty about their timing of consumption, banks are able to provide insurance against this uncertainty, also known as liquidity provision. However, when agents with different withdrawing needs are introduced, an adverse selection problem arises. Short-term deposits, which are less attractive to banks, have the incentive to join the contract offered to the ex ante uncertain customers. This will limit the ability of banks to provide insurance against uncertain withdrawal needs. When these short-term deposits a large enough, the insurance function of banks will be completely eliminated. On the other hand, potentially beneficial long-term deposits will stay out of the financial system.

When the quantitiy of short-term deposits is unpredictable, as in environments similar to Smith (2002) and Antinolfi and Keister (2006), a banking crisis may happen. When sufficiently large short-term funds are deposited,.bank reserves are exhausted and long-term investments need to be disrupted. The resulting crisis then has strong negative consequences for the entire economy. ${ }^{1}$ Incentive compatibility constraints that produce contracts where short-term funds choose not to deposit will prevent banking crises, but at the cost of losing the insurance function of banks. Restricting short-term deposits may not be optimal at all times, since the cost of doing so may be greater than the expected loss in allowing crises to occur with positive probability.

Other papers have reached related results in different environments. Fecht and Martin (2005) develop a model in which the degree of liquidity insurance offered to households through banks' deposit contracts is restrained by households' financial market access. They find that improved financial market access may reduce welfare by reducing risk sharing. Similarly, Jacklin (1987, 1993) shows that the insurance function provided by demand deposit contracts completely disappears if trading opportunities are introduced. Von Thadden (1997) develops a model where time is continuous, and shows that if agents are allowed to withdraw and re-invest their funds, the insurance function may not be incentive compatible. In our model, introducing heterogeneous agents reduces provision of liquidity, but does not completely eliminate it for small quantities of short-term deposits. For large quantities, the optimal bank contract will completely eliminate the service of liquidity provision.

The remainder of the paper proceeds as follows. Section 2 describes the environment and the benchmark, first-best allocation problem of the banks. The effect of short-term funds on the financial system is discussed in section 3. In section 4 we add aggregate uncertainty about withdrawal demand and discuss its implications. Section 5 concludes.

\footnotetext{
${ }^{1}$ See Ennis and Keister (2003) for the effect of crises on growth, and Caprio et al (2005) for evidence on the costs of banking crises.
} 


\section{The Model}

\section{$2.1 \quad$ Environment}

The model is a two asset version of the models developed by Bryant (1980) and Diamond and Dybvig (1983), where two types of agents are introduced. ${ }^{2}$ The economy is populated by a continuum of agents. Time is discrete and there are three periods indexed by $t=0,1,2$. Agents are endowed one unit of a single good when young, and nothing in periods 1 and 2 . They care only about consumption in periods 1 or 2 , and are expected utility maximizers. Their utility has the form $u(c)=c^{(1-\rho)} /(1-\rho)$, with the coefficient of relative risk aversion $\rho>1$.

There are two types of agents, who differ only in the time they learn their liquidity preference shock. Type $a$ (uninformed) agents are uncertain in period 0 , at the time investment decisions are made, about their preferences over consumption at dates 1 and 2 . They learn whether they will want to consume in period 1 or 2 at the beginning of period 1 . Let $\pi_{1}^{a}$ and $\pi_{2}^{a}$ be the total population of type $a$ impatient and patient agents, respectively, with $\pi_{1}^{a}+\pi_{2}^{a}=1$. There is no aggregate uncertainty for the total population or the share of domestic impatient and patient agents.

In contrast, type $b$ (informed) agents know at the time they are born whether they will prefer to consume in periods 1 or 2 . We label $\pi_{1}^{b}, \pi_{2}^{b}$ as the total population of impatient and patient type $b$ agents, respectively. ${ }^{3}$ Agents' type ( $a$ or $b$ ) is observable. Finally, the liquidity preference shock is private information for both types of agents.

Both types of agents have access to a linear production technology whereby one unit of the good invested in period 0 yields $R>1$ units of the good at time 2. This technology is illiquid, in the sense that an investment that is interrupted in period 1 generates $r<1$ units of consumption. In addition, there is a liquid storage technology, whose return is equal to 1 in both periods. In this sense, the liquid asset dominates the production technology in the shortrun, while investing in the production technology dominates the liquid asset in the long-run.

The timing of events follows. At the beginning of period 0 , young agents receive their endowments, and the informed type $b$ agents learn their liquidity preference. Agents then choose their portfolio allocation, i.e. the mix of storage and the illiquid investment. In period 1, type $a$ agents learn whether they will want to consume in periods 1 or 2 . Following this, period 1 consumption occurs, where the illiquid technology may be liquidated in order to be consumed. In period 2 the long-term investment technology matures, and patient agents consume.

\footnotetext{
${ }^{2}$ Bencivenga and Smith (1991) first introduce two assets in an OG-Diamond-Dybvig environment.

${ }^{3}$ Alternatively, we can think of the $\pi_{1}^{b}$ agents as Diamond-Dybvig agents with a larger share of impatient agents relative to type $a$ agents, where here we look at the limiting special case where all are impatient. Likewise, the $\pi_{2}^{b}$ agents have a lower probability relative to type $a$ 's of becoming impatient, set here at zero.
} 


\subsection{Banks}

Banks arise endogenously in our environment as a coalition of type $a$ agents. This is because uninformed agents benefit from pooling their resources in order to overcome idiosyncratic uncertainty, and they gain from insuring themselves against their liquidity preference shock. In contrast, informed agents face no uncertainty at the time the investment decision is made, and thus have no need to pool their resources, nor require insurance.

Banks announce contracts in period 0, which specify returns to depositors that depend on their liquidity preference (early vs late-withdrawers) reported by agents. After young agents deposit their endowments with banks, banks use these deposits to save in the liquid asset and make investments in the production technology. In period 1, type $a$ depositors learn whether they will withdraw in period 1 or 2 . Following this, banks pay to agents who wish to withdraw early. In period 2 the long-term investment matures, and banks dispense payments to the patient agents.

Consider initially as a benchmark, a separated world. That is, banks will be able to offer a contract to type $a$ uninformed agents only, where informed agents do not participate.

Let $\gamma$ denote the share of bank's liquid reserves. Denote $c_{1}^{a}$ and $c_{2}^{a}$ as consumption for type $a$ early and late-withdrawers, respectively. Then, the problem of the bank is

$$
V^{a} \equiv \max _{c_{1}^{a}, c_{2}^{a}} \pi_{1}^{a} u\left(c_{1}^{a}\right)+\left(1-\pi_{1}^{a}\right) u\left(c_{2}^{a}\right)
$$

subject to

$$
\begin{gathered}
\pi_{1}^{a} c_{1}^{a}=\gamma \\
\left(1-\pi_{1}^{a}\right) c_{2}^{a}=R(1-\gamma) \\
c_{2}^{a} \geq c_{1}^{a} \\
V^{a}>V^{\text {aut }} \\
c_{1}^{a}, c_{2}^{a} \geq 0
\end{gathered}
$$

Where (2) and (3) are the resource constraints, and (4) is the incentive compatibility or truth-telling constraint. (5) is the participation constraint, where $V^{a u t}$ is the indirect utility of type $a$ agents behaving in autarky. Given constant relative risk aversion preferences, the solution to this problem sets the share of liquid reserves as

$$
\gamma^{a}=\left[1+\frac{\left(1-\pi_{1}^{a}\right)}{\pi_{1}^{a}} R^{(1-\rho) / \rho}\right]^{-1} .
$$

Type $b$ informed agents, in contrast, are able to achieve their optimal outcome without the need for banks. Young type $b$ agents that know they will want to withdraw in the first period, can simply acquire the liquid asset, while late-withdrawers can invest all of their endowment in the illiquid technology in order to realize higher returns. Thus, consumption for type $b$ agents in a separated world will be $c_{1}^{b}=1$ and $c_{2}^{b}=R$. 
In contrast, (6) implies that the returns for type $a$ agents will have $c_{1}^{a}>1$, and $c_{2}^{a}<R$. The fact that returns differ across types may generate the incentives for agents to misrepresent their type.

Uninformed type $a$ agents choose to deposit all of their endowments in banks, since the expected utility of an agent whose funds are intermediated will be greater than the expected utility when they behave autarkically, i.e. $V^{a}>V^{\text {aut }}$. This is because financial intermediation in this model provides two services.

First, banks prevent suboptimal holding of assets. A coalition of agents takes advantage of the law of large numbers. Namely, while for individual agents $\pi$ is a probability, for banks it is a known share of agents. Therefore, banks could offer $c_{1}^{a}=1$ and $c_{2}^{a}=R$, an allocation not attainable under autarky. Notice that this is identical to the solution for informed agents. For this instance it is particularly clear to see that a coalition of agents completely resolves the idiosyncratic uncertainty about the timing of consumption, which is the distinction between both types of agents.

Second, banks provide insurance should agents become early-withdrawers. That is, $c_{1}^{a}>1$. This is achieved at the cost of foregoing some consumption if they are late-withdrawers, where $c_{2}^{a}<R$. This risk-sharing service that is realized through financial intermediation is what Diamond and Dybvig define as banks providing liquidity.

Finally, notice that the higher the level of risk aversion, the more agents value liquidity provision. This can be seen by noting that $\gamma^{\prime}(\rho)>0$. As risk aversion increases, in the limit $(\rho \longrightarrow \infty)$, we have $c_{1}^{a}=c_{2}^{a}$, where agents choose to fully insure against early consumption.

\section{Contracts with Both Types of Agents}

In this section we examine the more realistic case when type $b$ agents cannot be prevented from participating in the banking contract, if they wish to do so. Recall that types are observable. However, if type $b$ agents stand to gain by depositing in a bank, they can offer to share the profits with a type $a$ agent that is willing to deposit for them. While type $a$ agents collectively would like to thwart these associations from happening, at the individual level agents may consider these associations beneficial. This is the case as long as the marginal payoff from "cheating" is greater than its marginal individual cost. ${ }^{4}$ Given this, the problem of a bank now becomes

$$
V^{*} \equiv \max _{c_{1}, c_{2}} \pi_{1}^{a} u\left(c_{1}\right)+\left(1-\pi_{1}^{a}\right) u\left(c_{2}\right)
$$

subject to

$$
\lambda c_{1}=\gamma
$$

${ }^{4}$ The marginal individual cost is the marginal social cost divided by the number of type $a$ agents. Since we have a continuum of type $a$ agents, the individual marginal cost $\longrightarrow 0$. Therefore, whatever their relative bargaining power, as long as the share a cheating type $a$ receives is greater than zero, they will find associating beneficial. 


$$
\begin{gathered}
(1-\lambda) c_{2}=R(1-\gamma) \\
\phi_{1}^{b}=\left\{\begin{array}{ccc}
0 & \text { if } \quad c_{1} \leq 1 \\
\pi_{1}^{b} & \text { if } \quad c_{1}>1
\end{array}\right. \\
\phi_{2}^{b}=\left\{\begin{array}{ccc}
0 & \text { if } \quad c_{2} \leq R \\
\pi_{2}^{b} & \text { if } \quad c_{2}>R
\end{array}\right. \\
c_{2} \geq c_{1} \\
V^{*}>V^{a u t} \\
c_{1}, c_{2} \geq 0
\end{gathered}
$$

where $\lambda$ is the endogenous share of total impatient depositors given by

$$
\lambda=\frac{\pi_{1}^{a}+\phi_{1}^{b}}{\pi_{1}^{a}+\pi_{2}^{a}+\phi_{1}^{b}+\phi_{2}^{b}}
$$

In this problem, banks decide whether to allow type $b$ agents to enter by way of choice of the consumption schedule. This is described by the constraints (10) and (11), which are the participation constraints of type $b$ agents, where $\phi_{1}^{b}$ and $\phi_{2}^{b}$ are the number of impatient and patient type $b^{\prime}$ s that choose to enter, respectively ${ }^{5}$.

We begin the process of solving this problem by showing that an adverse selection problem arises, where patient type $b$ agents participating in the banking contract would increase welfare of type $a$ agents, but will never choose to deposit in banks.

Proposition $1 V^{* \prime}\left(\phi_{2}^{b}\right)>0$, and $\phi_{2}^{b}=0$ for $\rho>1$.

The proofs are contained in the appendix. In our problem, $\rho>1$ entails that early consumption will be greater or equal to one, and by feasibility, late consumption will be less than or equal to $R .^{6}$ Since the return for patient type $b$ 's in autarky equals $R$, they will not enter the banking contract. In contrast, impatient type $b$ agents may have the incentive to enter, depending on the value of $c_{1}$ chosen by banks, as described by the constraint (10).

Having ruled out the participation of patient type b's, we turn our attention to the bank's problem where only impatient type $b$ 's may want to deposit in a bank. Consider initially the pooling case where banks opt to let type $b$ 's enter, that is $\phi_{1}^{b}=\pi_{1}^{b}$. In this case, the solution to (7) sets the optimal reserve ratio, which we label $\gamma^{p}$, as

$$
\gamma^{p}=\left[1+\left(\frac{(1-\lambda)}{\lambda}\right)^{1-1 / \rho}\left(\frac{\left(1-\pi_{1}^{a}\right)}{\pi_{1}^{a}}\right)^{1 / \rho} R^{(1-\rho) / \rho}\right]^{-1}
$$

\footnotetext{
${ }^{5}$ Truly, when $c_{1}=1, \Rightarrow \phi_{1}^{b} \in\left[0, \pi_{1}^{b}\right]$, where type $b$ 's are indifferent between entering or not. In this case we assume for simplicity that they choose not enter.

${ }^{6}$ This result is reversed for $\rho \in(0,1)$, where $c_{1}<1$ and $c_{2}>R$, and thus patient type $b$ 's choose to enter the banking contract while the impatient choose not to participate.
} 
Proposition $2 c_{1}^{\prime}\left(\phi_{1}^{b}\right)<0$, and $\gamma^{p \prime}\left(\phi_{1}^{b}\right)>0$ for the pooling case.

Proposition 2 says that bank's liquidity provision service is reduced when type $b$ agents participate in the banking contract. However, the actual portfolio share that banks allocate to liquid reserves does increase with type $b^{\prime} s$ participation. This latter effect partially offsets the former. That is, banks will increase reserves to compensate for the loss of liquidity caused by the larger share of type $b$ agents.

However, type $a$ agents may prefer a contract that gives informed impatient agents the incentive not to deposit in banks. Consider the separating case where $\phi_{1}^{b}=0$. This implies from the participation constraint (10) that period 1 consumption needs to be set to $c_{1} \leq 1$. It follows that from resource constraint (8), the solution sets

$$
\gamma^{s}=\pi_{1}^{a}
$$

Proposition 3 Define the threshold

$$
\widehat{\pi}_{1}^{b}=\pi_{1}^{a}\left(R^{\rho-1}-1\right)
$$

Then the solution to the bank's problem is the contract $\left(c_{1}, c_{2}\right)$ given by

$$
\begin{aligned}
& \left.\begin{array}{l}
c_{1}=\frac{1}{\lambda} \gamma^{p} \\
c_{2}=\frac{R}{(1-\lambda)}\left(1-\gamma^{p}\right)
\end{array}\right\} \quad \text { for } \pi_{1}^{b} \leq \widehat{\pi}_{1}^{b} \\
& \left.\begin{array}{l}
c_{1}=1 \\
c_{2}=R
\end{array}\right\} \quad \text { for } \pi_{1}^{b}>\widehat{\pi}_{1}^{b}
\end{aligned}
$$

The solution portrays the trade-off between the bank's contract providing insurance and the loss of resources to type $b$ agents who exploit this service. When type $a$ agents implement a risk-sharing contract, they redistribute resources from late to early-withdrawers. Therefore, when informed early-withdrawers enter this contract, they are receiving transfers from type $a$ late-withdrawers. This unintended transfer of goods reduces the welfare of type $a$ agents. This adds another layer to the adverse selection problem: detrimental short-term type $b$ deposits participate in the banking contract, while, as noted above, beneficial patient type $b^{\prime}$ s choose not to participate. For a small enough share of type $b$ agents, type $a$ agents will prefer the loss of transferring some resources rather than give up the insurance service. Conversely, for shares of type $b$ impatient agents greater than $\widehat{\pi}_{1}^{b}$, agents will prefer the self-selection outcome. Here the cost of subsidizing type $b$ 's consumption exceeds the benefits of insurance, so separation is chosen.

Notice that the threshold $\widehat{\pi}_{1}^{b}$ given by (15) is increasing in $\pi_{1}^{a}, \rho$ and $R$. That is, when $\pi_{1}^{a}$ is large, then a bigger share of agents benefit from insurance and thus the threshold at which they want to give it up is larger. ${ }^{7}$ Also, the higher the degree of risk aversion, the more agents value insurance, and thus

\footnotetext{
${ }^{7}$ However, as $\pi_{1}^{a}$ increases, the amount of insurance they obtain is smaller, which works in the opposite direction.
} 
are less willing to sacrifice this function of banks. In the limit we have that as $\rho \rightarrow \infty, \widehat{\pi}_{1}^{b} \rightarrow \infty$. Finally, the higher the return on the production technology, the higher intertemporal transfers, and thus the threshold at which domestic agents are willing to give up insurance is raised.

Lastly notice that while insurance is reduced in the pooling case, or is completely lost for the separating case, type $a$ agents still prefer to deposit their endowments in banks. This is so since the other service banks provide, efficient intertemporal investment, is still achieved. However, as $r \rightarrow 1, V^{*} \rightarrow V^{\text {aut }}$ for $\pi_{1}^{b}>\widehat{\pi}_{1}^{b}$. That is, as the potential cost of holding the production technology disappears, banks lose their role when they do not provide insurance.

\section{Banking Crises}

In this section we assume aggregate uncertainty about withdrawal demand, similar to Smith (2002) and Antinolfi and Keister (2006). Here we assume that the quantity of type $b$ agents, $\pi_{1}^{b}$ is now a random variable whose realization is unknown at the time banks make the portfolio decision. As in the previous section, patient type $b$ agents will never find it optimal to deposit in banks for $\rho>1$.

The timing of events follows. Banks announce contracts in period 0. Based on the contract banks offer, agents choose whether to deposit or not. Banks then receive deposits and choose the portfolio allocation. After type $a$ depositors learn their type, agents who wish to withdraw early report to banks, at which time $\pi_{1}^{b}$ is revealed. Following this, banks pay to agents based on this new information. In period 2 the production technology matures, and banks dispense payments to the remaining patient agents.

Define $\pi_{1}=\frac{\pi_{1}^{a}+\pi_{1}^{b}}{\pi_{1}^{a}+\pi_{2}^{a}+\pi_{1}^{b}}$ as the total share of impatient agents, its value drawn from a distribution $G\left(\pi_{1}\right)$ with pdf $g\left(\pi_{1}\right)$, which is common knowledge, and with finite support in the interval $\left[\pi_{1}^{a}, 1\right]$. Then, the bank's problem is given by

$$
\tilde{V} \equiv \max _{\substack{c_{1}\left(\pi_{1}\right), c_{2}\left(\pi_{1}\right) \\ \alpha, \delta}} \int_{\pi_{1}^{a}}^{1}\left[\pi_{1}^{a} u\left(c_{1}\right)+\left(1-\pi_{1}^{a}\right) u\left(c_{2}\right)\right] g\left(\pi_{1}\right) d \pi_{1}
$$

subject to

$$
\begin{aligned}
& \lambda c_{1}=\alpha \gamma+\delta r(1-\gamma) \\
& (1-\lambda) c_{2}=(1-\alpha) \gamma+(1-\delta) R(1-\gamma) \\
& \phi_{1}^{b}=\left\{\begin{array}{ccc}
0 & \text { if } & \int_{\pi_{1}^{a}}^{1} u\left(c_{1}\right) g\left(\pi_{1}\right) d \pi_{1} \leq u(1) \\
& & \int_{1}^{b} \\
& \text { if } & \int_{\pi_{1}^{a}}^{1} u\left(c_{1}\right) g\left(\pi_{1}\right) d \pi_{1}>u(1)
\end{array}\right. \\
& c_{2} \geq c_{1}
\end{aligned}
$$




$$
\begin{gathered}
\tilde{V}>V^{\text {aut }} \\
c_{1}, c_{2} \geq 0, \quad 0 \leq \alpha \leq 1, \quad 0 \leq \delta \leq 1
\end{gathered}
$$

Where $\alpha$ and $\delta$ represent the fraction of liquid reserves and investments, respectively, that banks liquidate in period one. They capture the fact that with aggregate uncertainty, banks at times may hold liquid reserves across periods for low realizations of $\pi_{1}^{b}$, or may have to scrap investments in order to meet liquidity needs of early-withdrawers for high realizations of $\pi_{1}^{b}$. (20) is the participation constraint for impatient type $b$ agents.

Here again, it is feasible for domestic banks to choose a separating contract by announcing $c_{1}$ such that the incentive compatibility constraint

$$
\int_{\pi_{1}^{a}}^{1} u\left(c_{1}\right) g\left(\pi_{1}\right) d \pi_{1} \leq u(1)
$$

is satisfied. Then type $b$ agents choose not to enter, and thus $\lambda=\pi_{1}^{a}$. It follows that by no aggregate uncertainty, (21) becomes $u\left(c_{1}\right) \leq u(1)$, which binds at $c_{1}=1$, as in the previous section. ${ }^{8}$

Consider now the pooling case where type $b$ agents choose to deposit their endowments. Here we have $\lambda=\pi_{1}$, which implies aggregate uncertainty. That is, banks learn the share of early-withdrawers only after the portfolio decision has been made.

We start by solving for the optimal fractions of reserves and investments that banks liquidate, $\alpha$ and $\delta$. Efficiency in holding investments dictates that if $\alpha<1$, then $\delta=0$, and if $\delta>0$ then $\alpha=1$.

When demand for liquidity is relatively low, banks will have excess reserves, and some reserves will be forwarded to the next period.

The optimal fraction of reserves banks liquidate, $\alpha$, needs to satisfy the incentive compatibility constraint $c_{2} \geq c_{1}$. Substituting (18) and (19) into this constraint and solving for $\alpha$ with $\delta=0$, we arrive at the optimal reserves liquidation strategy

$$
\alpha=\left\{\begin{array}{cc}
\pi_{1}\left(1+R \frac{(1-\gamma)}{\gamma}\right) & \text { for } \pi_{1} \leq \underline{\pi}_{1} \\
1 & \text { for } \pi_{1}>\underline{\pi}_{1}
\end{array}\right.
$$

where

$$
\underline{\pi}_{1}=\frac{\gamma}{\gamma+(1-\gamma) R}
$$

is the threshold below which $\alpha<1$, and follows from solving for $\pi_{1}$ in the incentive compatibility constraint, setting $\alpha=1$ and $\delta=0 . \quad \underline{\pi}_{1}$ is the kink in the constraint set, above which all reserves are given to impatient agents.

\footnotetext{
${ }^{8}$ Also by no aggragate uncertainty, the term in brackets in the objective function (17) can be pulled out of the integral, and $\alpha=1, \delta=0$ in the constraints (18) and (19), and thus assets are held optimally.
} 
To find the investment liquidation strategy, $\delta$, note that it will not be optimal for banks to liquidate investments as long as

$$
\frac{u^{\prime}\left(c_{1}\right)}{u^{\prime}\left(c_{2}\right)} \leq \frac{R}{r}
$$

That is the point at which marginal rate of substitution between liquidating investments and allowing them to mature is less than or equal the marginal rate of transformation. Substituting (18) and (19), noting that $u^{\prime}\left(c_{1}\right)=c_{1}^{-\rho}$ for our CRRA utility form, and solving for $\delta$ with $\alpha=1$ in (24) we have the optimal investment liquidation strategy

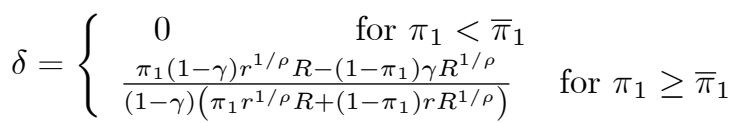

where the threshold

$$
\bar{\pi}_{1}=\frac{\gamma}{\gamma+(1-\gamma) R^{1-1 / \rho} r^{1 / \rho}}
$$

is the point at which $M R S=M R T$ with $\delta=0$ and $\alpha=1$. Substituting the optimal $\alpha$ and $\delta$ into the bank's budget constraints (18) and (19), we arrive at the optimal return schedule in the pooling case

$$
\begin{aligned}
& c_{1}=c_{2}=\gamma+R(1-\gamma) \quad \text { for } \quad \pi_{1} \in\left(\pi_{1}^{a}, \underline{\pi}_{1}\right) \\
& \left.\begin{array}{l}
c_{1}=\frac{1}{\pi_{1}} \gamma \\
c_{2}=\frac{R}{\left(1-\pi_{1}\right)}(1-\gamma)
\end{array}\right\} \quad \text { for } \pi_{1} \in\left(\underline{\pi}_{1}, \bar{\pi}_{1}\right) \\
& \left.\begin{array}{l}
c_{1}=r^{1 / \rho} \eta \\
c_{2}=R^{1 / \rho} \eta
\end{array}\right\} \quad \text { for } \pi_{1} \in\left(\bar{\pi}_{1}, 1\right)
\end{aligned}
$$

where $\eta=\frac{R(r(1-\gamma)+\gamma)}{\pi_{1} r^{1 / \rho} R+\left(1-\pi_{1}\right) r R^{1 / \rho}}$. We now solve for the optimal reserve ratio $\gamma$, by substituting the return schedule above into the objective function(17). Then the bank's objective function for the pooling case can then be written as

$$
\begin{aligned}
\tilde{V} \equiv & \max _{\gamma} \int_{\pi_{1}^{a}}^{\underline{\pi}_{1}} u(\gamma+R(1-\gamma)) \\
& +\int_{\underline{\pi}_{1}}^{\bar{\pi}_{1}}\left[\pi_{1}^{a} u\left(\frac{1}{\pi_{1}} \gamma\right)+\left(1-\pi_{1}^{a}\right) u\left(\frac{R}{\left(1-\pi_{1}\right)}(1-\gamma)\right)\right] g\left(\pi_{1}\right) d \pi_{1} \\
& +\int_{\bar{\pi}_{1}}^{1}\left[\pi_{1}^{a} u\left(r^{1 / \rho} \eta\right)+\left(1-\pi_{1}^{a}\right) u\left(R^{1 / \rho} \eta\right)\right] g\left(\pi_{1}\right) d \pi_{1}
\end{aligned}
$$

where the optimal share of liquid reserves is implicitly defined by the solution to this problem. 
Banks in this case provide full insurance for withdrawal demand in $\left(\pi_{1}^{a}, \underline{\pi}_{1}\right)$. Here, $\alpha<1$ and some liquid reserves will be forwarded to the next period. For withdrawals in $\left(\underline{\pi}_{1}, \bar{\pi}_{1}\right)$, reserves are exhausted, and impatient get lower returns than patient agents. However, $\delta=0$ so that no early liquidation of the production technology is carried out. Lastly, when withdrawal demand exceeds $\bar{\pi}_{1}, \delta>0$ where banks interrupt the production process in order to satisfy the increased share of early withdrawals.

Similar to the case where the share of impatient agents is known, expected utility of type $a$ depositors is reduced as type $b$ agents enter the banking contract. In this case this is so for two reasons. First, type $a$ agents that value insurance end up transferring resources to type $b$ agents for low realizations of $\pi_{1}$. Second, here the uncertainty of withdrawal demand potentially forces both assets to be used suboptimally. That is, liquid assets are held in excess for low realizations of $\pi_{1}$, while for high realizations the production technology is liquidated early. Further, for $\pi_{1} \in\left(\bar{\pi}_{1}, 1\right)$, both services that banks provide, insurance and optimal intertemporal investment, are lost.

Consider a numerical example to illustrate this. ${ }^{9} \quad$ Specifically, assume a uniform distribution $G\left(\pi_{1}\right)$ with pdf $g\left(\pi_{1}\right)=1 /\left(1-\pi_{1}^{a}\right)$, and consider the following parameters: the coefficient of relative risk aversion is $\rho=4$, the share of domestic impatient agents is $\pi_{1}^{a}=0.5$ and the return to investments, are $R=3$ and $r=0.5$. In this case the solution to (28) sets $\gamma=0.82$, with $\underline{\pi}_{1}=0.6$ and $\bar{\pi}_{1}=0.7$. Figure 1 depicts our example's consumption schedule as a function of the uncertain withdrawal demand. Notice that for realizations of $\pi_{1}>0.876$, both liquidity provision is lost and the long-term investments are being liquidated early. In this case even the informed type $b$ agents are ex-post worse off.

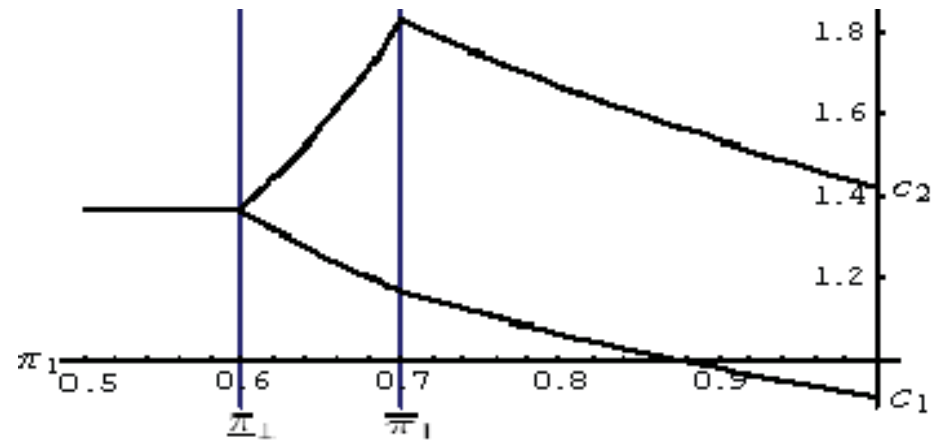

Figure 1

The following proposition summarizes the above results.

Proposition 4 The separating case sets the return vector $\left(c_{1}, c_{2}\right)=(1, R)$ with optimal reserves $\gamma^{s}=\pi_{1}^{a}$. For the pooling case, the optimal return schedule and the objective function are given by (27) and (28). Finally, define $\tilde{V}^{p}$ and $\tilde{V}^{s}$ as

\footnotetext{
${ }^{9}$ All computations are performed in Mathematica. Code available upon request.
} 
the values to the pooling and separating indirect utilities. Then the solution to the problem given in (17) satisfies $\tilde{V}=\max \left\{\tilde{V}^{p}, \tilde{V}^{s}\right\}$.

For certain parameters, type $a$ agents will ex-ante prefer the pooling contract where banking crises may occur, while for others they will prefer the separating contract. To illustrate this welfare trade-off, consider our previous numerical example. Given these parameters, the indirect utilities are $\tilde{V}^{p}=-0.172$ and $\tilde{V}^{s}=-0.173$, where the pooling contract is preferred. In contrast, if we lower the return to investments to $R=2$, leaving all other parameters unchanged, we get $\tilde{V}^{p}=-0.209$ and $\tilde{V}^{s}=-0.188$. It follows that for this case the separating contract is chosen. Similarly, decreasing the coefficient of relative risk aversion $\rho$ reduces the parameter set at which the pooling contract is preferred.

The contract where agents self-select comes at the cost of losing the service of liquidity provision but allows for optimal intertemporal holding of assets, and a banking crisis will be ruled out. In contrast, the pooling contract will not be able to prevent suboptimal holding of assets, and may or may not be able to provide insurance. That is, for low quantities of type $b$ agents it will provide insurance, but will not be able to for large quantities of unpredicted early withdrawals.

\section{Conclusion}

This paper studies the effects that heterogeneous agents have on the financial system in the context of a demand deposit banking model. When banks are not able to distinguish among agents, informed impatient agents have the incentive to enter the banking contract to take advantage of the insurance service that banks provide, at the expense of uninformed agents. Banks are able to restrict these deposits by way of an incentive compatibility constraint, but at the cost of losing the insurance function of banks. Finally, when the quantity of informed agents is unknown, then a banking crisis may occur. In this case an incentive compatible contract will curtail liquidity provision but also prevent banking crises. Still, the cost of imposing a self selection constraint may outweigh its benefits. Given this, it would be interesting to look at ways in which deposits could be restricted without losing the insurance service that banks provide.

\section{Appendix}

\subsection{Proof of Proposition 1}

To show that utility is increasing in the number of patient type $b$ agents, $V^{* \prime}\left(\phi_{2}^{b}\right)>0$, first notice that $\lambda^{\prime}\left(\phi_{2}^{b}\right)<0$, so that $V^{* \prime}(\lambda)<0$ entails $V^{* \prime}\left(\phi_{2}^{b}\right)>0$. Next notice that the first order condition to our problem given by $(7)$ sets

$$
\gamma=\left[1+\left(\frac{(1-\lambda)}{\lambda}\right)^{1-1 / \rho}\left(\frac{\left(1-\pi_{1}^{a}\right)}{\pi_{1}^{a}}\right)^{1 / \rho} R^{(1-\rho) / \rho}\right]^{-1}
$$


Now taking $V^{* \prime}(\lambda)$ from (7), and setting it to $<0$, we have

$$
V^{* \prime}(\lambda)=-\frac{\pi_{1}^{a} \gamma\left(\frac{m}{\lambda}\right)^{-\rho}}{\lambda^{2}}+\frac{\left(1-\pi_{1}^{a}\right)(1-\gamma) R\left[\frac{(1-\gamma) R}{(1-\lambda)}\right]^{-\rho}}{(1-\lambda)^{2}}<0
$$

after some algebra, substituting in (29) and taking the natural log to the remaining expression, we have

$$
\frac{(2 \rho-1)}{\rho} \ln \left(\frac{\pi_{1}^{a}}{\lambda} \frac{(1-\lambda)}{\left(1-\pi_{1}^{a}\right)}\right)>\frac{(1-\rho)}{\rho} \ln (R)
$$

Since $\pi_{1}^{a}>\lambda$ in this case, and $R>1$, both expressions inside the logs are greater than one, and thus their log expressions are positive. Thus the above expression is always true for $\rho>1$, since the $l h s>0$ and the $r h s<0$. Hence $V^{* \prime}\left(\phi_{2}^{b}\right)>0$ always.

To show that $\phi_{2}^{b}=0$ for $\rho>1$, suppose the opposite, that is, that type $b$ patient agents choose to deposit in a bank. Then $\phi_{2}^{b}=\pi_{2}^{b}$, and by (11) $c_{2}>R$. It follows that $c_{1}<1$ by the feasibility constraints. Also, $c_{1}<1$ implies $m<\lambda$ by (8). Thus we have

$$
\left[1+\left(\frac{(1-\lambda)}{\lambda}\right)^{1-1 / \rho}\left(\frac{\left(1-\pi_{1}^{a}\right)}{\pi_{1}^{a}}\right)^{1 / \rho} R^{(1-\rho) / \rho}\right]^{-1}<\lambda
$$

after some algebra and taking the natural log to the remaining expression, we have

$$
\ln \left(\frac{(1-\lambda)}{\left(1-\pi_{1}^{a}\right)} \frac{\pi_{1}^{a}}{\lambda}\right)<(1-\rho) \ln (R)
$$

Which is a contradiction for $\rho>1$, since both expressions inside the logs are greater than one, and thus their log expressions are positive.

\subsection{Proof of Proposition 2:}

For $c_{1}$, first notice that $\lambda$ increases with $\phi_{1}^{b}$, and thus we can evaluate $c_{1}^{\prime}(\lambda)$, where $c_{1}=\frac{\gamma^{p}}{\lambda}$ and $\gamma^{p}$ is given by (13). Then evaluate $c_{1}^{\prime}(\lambda)$ at lambda's lower bound, $\lambda \rightarrow \pi_{1}^{a}$. After some algebra on this first derivative, we arrive at

$$
\frac{R\left(R^{1 / \rho}-R\right)}{\left(\pi_{1}^{a} R+\left(1-\pi_{1}^{a}\right) R^{1 / \rho}\right)^{2}}
$$

which is less than zero for $\rho>1$. Thus we have $c_{1}^{\prime}(\lambda)<0$ at the lower bound. Also notice that $c_{1}>1$ in this case. Next notice that when

$$
\lambda \rightarrow \hat{\lambda}=\left(1+\frac{\left(1-\pi_{1}^{a}\right)}{\pi_{1}^{a}} R^{1-\rho}\right)^{-1}
$$

we have $c_{1}=1$. $\hat{\lambda}$ is lambda's upper bound, beyond it type $a$ agents will choose to self select. Since $c_{1}^{\prime}$ does not change signs, and $c_{1}$ goes from greater than one to equal to one as lambda increases, we have $c_{1}^{\prime}(\lambda)<0$ always. 
For the second part of the proposition, it is straightforward to sign the derivative of $\gamma^{p}$, so that $\gamma^{p \prime}\left(\phi_{1}^{b}\right)>0$ always.

\subsection{Proof of Proposition 3:}

The optimal reserve ratios that solve for the pooling and separating outcomes are $\gamma^{p}$ and $\gamma^{s}$ given by (13) and (14), respectively. Then the threshold $\widehat{\pi}_{1}^{b}$ given by (15) follows from setting $c_{1}^{p}=c_{1}^{s}$ and solving for $\pi_{1}^{b}$, such that $V^{* \text { pool }}=V^{* s e p}$ is satisfied.

Consider first the pooling case. Then $\lambda=\frac{\pi_{1}^{a}+\pi_{1}^{b}}{1+\pi_{1}^{b}}$. Further suppose that that $\pi_{1}^{b}$ is small enough so that $\lambda$ is arbitrarily close to $\pi_{1}^{a}$. It follows that $\gamma^{p}$ is arbitrarily close to the benchmark $\gamma^{a}$ given by (6). Thus $V^{* p o o l}$ is arbitrarily close to $V^{a}$, and the pooling contract is preferred to a separating contract. Then, by continuity, the threshold $\widehat{\pi}_{1}^{b}$ satisfies $\phi_{1}^{b}=\pi_{1}^{b}$ (pooling) for $\pi_{1}^{b} \leq \widehat{\pi}_{1}^{b}$, and $\phi_{1}^{b}=0$ (separating) for $\pi_{1}^{b}>\widehat{\pi}_{1}^{b}$.

\subsection{Proof of Proposition 4:}

The derivation of the separating and pooling cases closely follow the discussions in the body of the paper. For the remaining part, consider a degenerate distribution $G\left(\pi_{1}\right)$ that places mass 1 to an arbitrarily small $\pi_{1}^{b}$, such that $\tilde{V}^{p}$ is arbitrarily close to $V^{a}$, the benchmark indirect utility. Then $\tilde{V}^{p}>\tilde{V}^{s}$, and pooling is preferred. Then, by continuity of the von Neumann-Morgenstern expected utility function, a threshold exists at which $\tilde{V}^{p}=\tilde{V}^{s}$. Beyond this threshold, the probability of large $\pi_{1}^{b}$ is such that $\tilde{V}^{p}<\tilde{V}^{s}$.

\section{References}

[1] Antinolfi, G., Keister,T.: Discount window policy, banking crises, and indeterminacy of equilibrium. Macroeconomic Dynamics 10, 1-19 (2006).

[2] Bencivenga, V., and Smith, B.: Financial Intermediation and Endogenous Growth. Review of Economic Studies 58, 195-209 (1991).

[3] Bryant, J.: A model of reserves, bank runs, and deposit insurance. Journal of Banking and Finance 4, 335-344 (1980)

[4] Caprio, G. Klingebiel, D., Laeven, L., Noguera, G.: Banking Crisis Database. In: Honohan, P., Laeven, L. (eds.) Systemic Financial Crises: Containment and Resolution, 2005, pp. 307-40, Cambridge and New York: Cambridge University Press.

[5] Diamond, D., Dybvig, P.: Bank runs, deposit insurance and liquidity. Journal of Political Economy 85, 191-206 (1983).

[6] Ennis, H., Keister, T.: Economic Growth, Liquidity and Bank Runs. Journal of Economic Theory, 109 220-245 (2003) 
[7] Fecht, F., Martin, A.: Banks, Markets and Efficiency. Federal Reserve Bank of New York Staff Reports No 210, (2005).

[8] Jacklin, C.: Demand deposits, trading restrictions, and risk sharing. In: Prescott, E., Wallace, N. (eds.), Contractual Arrangements for Intertemporal Trade, University of Minnesota Press, Minneapolis, 26-47.

[9] Jacklin, C. J.: Market rate versus fixed rate demand deposits. Journal of Monetary Economics 32, 237-258.(1993).

[10] Smith, B.: Monetary policy, banking crises and the friedman rule. AER Papers and Proceedings 92, 128-134 (2002).

[11] von Thadden, E.: The term structure of investments and the bank's insurance function. European Economic Review 41, 1355-1374 (1997). 